\title{
Growth Factor Mediated Assembly of Cell Receptor-Responsive Hydrogels
}

\author{
Nori Yamaguchi ${ }^{\dagger}$, Le Zhang ${ }^{\dagger}$, Byeong-Seok Chae ${ }^{\ddagger}$, Chandra S. Palla ${ }^{\ddagger}$, Eric M. Furst ${ }^{\ddagger}$, and \\ Kristi L. Kiick ${ }^{\dagger}$ \\ Department of Materials Science and Engineering and Department of Chemical Engineering, \\ UniVersity of Delaware, Newark, Delaware 19716
}

\begin{abstract}
The noncovalent assembly of polymeric materials via specific molecular recognition interactions has become increasingly prominent in the production of responsive, reversible, and injectable hydrogels. While protein-protein interactions predominantly have been used for such assembly, ${ }^{1-4}$ the use of extracellular matrix (ECM)-derived polysaccharide-peptide interactions has been recently emerging as an assembly approach. ${ }^{5-9}$ The interactions of proteins and glycosaminoglycans are critical in mediating the multiple responses of the ECM, and materials in which assembly and mechanical properties are controlled by such molecular recognition events may be useful for biologically directed targeted delivery. Accordingly, the ability of heparin and related glycosaminoglycans to sequester and stabilize growth factors has been exploited in the production of surfaces and covalently crosslinked hydrogels that can mediate cell proliferation and migration, angiogenesis, and wound healing. ${ }^{10-14}$ In particular, the controlled delivery of VEGF (vascular endothelial growth factor) and select other growth factors from polymeric matrices has shown potential for use in vascular therapies. $12,15,16$ Noncovalently assembled matrices also have similar potential use in this regard. ${ }^{-9}$
\end{abstract}

Here, we report the assembly, rheological properties, and targeted delivery/erosion profiles of noncovalently associated hydrogel networks produced via the interaction of a low-molecularweight heparin-modified star polymer (PEG-LMWH) and a dimeric, heparin-binding growth factor (VEGF). ${ }^{17}$ Given that overexpression of VEGF and other growth factor receptors plays a key role in both normal healing and pathological conditions, ${ }^{18-20}$ we reasoned that hydrogels assembled via such strategies may provide unique opportunities for stimuli-responsive delivery and erosion via biologically relevant, ligand-exchange mechanisms. A schematic of the assembly and erosion strategy is illustrated in Figure 1. We have focused on LMWH in these investigations in order to maximize intermolecular dimeric growth factor/LMWH binding over intramolecular binding (see Supporting Information). The PEGLMWH employed in these investigations was produced via Michael addition of thiol-terminated four-arm star PEG to maleimidefunctionalized LMWH. ${ }^{7}$ NMR characterization of the purified product indicated at least $75 \%$ functionalization of PEG-LMWH, indicating that it is of sufficiently high functionality $(f>2)$ to permit formation of crosslinked networks upon interaction with VEGF $(f=2)$. The VEGF was expressed from E. coli and purified via heparin-affinity chromatography as previously described (Supporting Information). ${ }^{16}$

Correspondence to: Kristi L. Kiick.

E-mail: kiick@udel.edu.

tDepartment of Materials Science and Engineering.

\$Department of Chemical Engineering.

Supporting Information Available: Expression of VEGF, optical tweezer microrheology experiments, VEGF release assays, cell proliferation assays. This material is available free of charge via the Internet at http://pubs.acs.org. 
Hydrogels were formed via the mixing of homogeneous, lowviscosity solutions of each component in phosphate buffered saline (PBS). The PEG-LMWH solution was vortexed to ensure homogeneity. Addition of a solution of VEGF $(5 \mu \mathrm{L}, 2 \mathrm{mg} / \mathrm{mL})$ to a solution of PEGLMWH $(5 \mu \mathrm{L}, 80 \mathrm{mg} / \mathrm{mL})$ immediately resulted in the formation of a self-supporting, viscoelastic hydrogel; the gel was thoroughly mixed via pipetting. The optical tweezer microrheological characterization of these hydrogel networks is shown in Figure 2a; experimental details about the microrheology experiment can be found in the Supporting Information. The apparently lowviscosity PEG-LMWH solutions exhibit storage moduli, $G^{\prime}(w) \approx 0.7 \mathrm{~Pa}$, in excess of the loss moduli $G^{\prime \prime}(w)$ at low frequencies, indicating a weak viscoelastic material, consistent with our previously reported results. ${ }^{8}$ Upon addition of VEGF to these solutions, an increase in elastic modulus is observed, with no statistically significant increase observed upon the addition of a control protein, BSA (bovine serum albumin). Figure $2 \mathrm{~b}$ compares the storage moduli of the PEG-LMWH solutions with those containing BSA and VEGF and clearly demonstrates the effective crosslinking by VEGF in the VEGF-containing PEG-LMWH samples. That the crosslinking is mediated by VEGF-LMWH interactions was also confirmed by the addition of free LMWH to the PEG-LMWH/ VEGF gels, which immediately liquefied the samples. VEGF-containing samples with polymer concentrations of $8 \mathrm{wt} \%$ resulted in elastic gels in which probe particles could not be moved by the optical trap, indicating a $G^{\prime}(w)>10 \mathrm{~Pa}$, whereas the modulus in the absence of VEGF was $G^{\prime}(w) \approx 1 \mathrm{~Pa}$.

An important outcome of the production of hydrogel networks via these strategies is the potential for receptor-mediated gel erosion; VEGF cross-links could be selectively removed in the presence of VEGF receptors that control proliferation and migration of vascular endothelial cells. ${ }^{21}$ Receptor-mediated targeting of VEGF-modified drug vehicles to VEGFR-2-expressing cells has been previously demonstrated, ${ }^{22-25}$ and a VEGFR-1 binding peptide has been shown to target a chlorin-type photosensitizer to human endothelial cells.

26 Given the primary role of VEGFR-2 in controlling cell proliferation and migration, ${ }^{21}$ the ability of the hydrogels to release VEGF in a VEGFR-2-responsive manner was probed in in vitro release assays (Supporting Information). The cumulative amount of ${ }^{125}$ I-labeled VEGF released from the hydrogels at specific timepoints was quantified via $\gamma$-counting. Polystyrene particles $(1 \mu \mathrm{m}, \mathrm{PS})$ were incubated with the hydrogels to study targeted erosion, as unmodified PS particles did not show any evidence of interfering with hydrogel assembly during the microrheology experiments. In one case, the particles were passivated via covalent attachment of anti-IgG (negative control), and in the second case, the anti-IgG nanoparticles were modified with a VEGFR-2-IgG conjugate (Supporting Information).

As observed in the data in Figure 2c, the PEG-LMWH/VEGF hydrogels incubated in PBS demonstrate a total cumulative release of approximately $30 \%$ over the 10 -day time period, while those incubated in the presence of PS/anti-IgG show a cumulative passive release of $40 \%$. In contrast, however, hydrogel samples incubated in the presence of PS/VEGFR-2 demonstrated increased rates of VEGF release and a total release of nearly $80 \%$. Importantly, hydrogels incubated with PS/VEGFR-2 visibly eroded after day 4 (Figure 2C, asterisk); the subsequent release data was obtained from a limited number of eroded samples that retained a small amount of weak gel, resulting in the inconsistent release rate. In all other cases, the hydrogels remained intact over the course of the experiment. Although the precise extent of erosion of the networks could not be quantified owing to the very small amounts of sample employed, these results clearly illustrate the potential for receptor-mediated VEGF delivery and erosion of these hydrogels and suggest opportunities for targeted erosion in response to other VEGF-binding receptors (e.g., VEGFR-1).

The bioactivity of VEGF released from the erodible hydrogels was also assessed in cellproliferation assays. In these assays, the proliferation of porcine aortic endothelial cells (PAE $\mathrm{KDR}$ ) in the presence of gels was monitored over time via cytometry methods (Supporting 
Information) and via live/dead assays with confocal microscopy imaging. The assessment of cell proliferation and gel erosion with cells encapsulated directly in the gels was not possible given the nonadhesive character of these PEG-based materials. A plot of the normalized number of cells under each condition, at each timepoint, is presented in Figure 3a. Confocal images illustrating the overlaid live/dead fluorescent staining of the cells in the presence of PEG-LMWH and PEG-LMWH/VEGF are shown in Figure 3b,c. The PEG-LMWH alone does not cause any increase in cell proliferation over the control (no polymer, no VEGF), while the PEG-LMWH/VEGF hydrogels show a statistically significant increase in proliferation (noted by an asterisk) over the PEG-LMWH samples as early as day 1 (Figure 3a). Different amounts of VEGF were included in the two gels in order to probe a range of proliferative responses (Supporting Information). The very low number of dead cells (red) observed via confocal microscopy confirms the lack of cytotoxicity of these materials (Supporting Information).

These results clearly demonstrate that therapeutically relevant growth factors can serve as elastic cross-links in noncovalently assembled hydrogel networks and that these networks can be selectively eroded in the presence of the growth factor receptors. The VEGF released from these hydrogels increases proliferation of VEGF-responsive cell lines, and coupled with the release and erosion data, suggest a novel potential mechanism for targeted delivery and erosion via the release of therapeutically important protein cross-links in response to cell surface receptors. The selective erosion of the materials in cellular assays, along with more quantitative assessment of the impact of the co-release of VEGF and PEG-LMWH on receptor activation, is currently under investigation. The therapeutic relevance of other dimeric heparin-binding growth factors, as well as opportunities for designing peptides with specific affinities and therapeutic action, suggests broader opportunities for these strategies in the production of responsive matrices for biomedical applications.

\section{Acknowledgment}

This work has been funded by the National Institutes of Health (K.L.K. and E.M.F.) Grant 1-R01-EB003172-01, the Camille and Henry Dreyfus Foundation (K.L.K.), and the Arnold and Mabel Beckman Foundation (K.L.K.). We gratefully acknowledge Prof. Andreas Zisch (IBT Zurich) for donation of the plasmid encoding VEGF, Dr. William Cain (University of Delaware) for assistance with ${ }^{125}$ I-labeling of VEGF, and Dr. Joseph Backer (Sibtech) for the donation of the PAE cell lines.

\section{References}

(1). Petka WA, Harden JL, McGrath KP, Wirtz D, Tirrell DA. Science 1998;281:389-392. [PubMed: 9665877]

(2). Miyata T, Asami N, Uragami T. Nature 1999;399:766-769. [PubMed: 10391240]

(3). Xu CY, Breedveld V, Kopecek J. Biomacromolecules 2005;6:1739-1749. [PubMed: 15877401]

(4). Wang C, Stewart RJ, Kopecek J. Nature 1999;397:417-420. [PubMed: 9989405]

(5). Seal BL, Panitch A. Biomacromolecules 2003;4:1572-1582. [PubMed: 14606882]

(6). Seal BL, Panitch A. Macromolecules 2006;39:2268-2274.

(7). Yamaguchi N, Kiick KL. Biomacromolecules 2005;6:1921-1930. [PubMed: 16004429]

(8). Yamaguchi N, Chae BS, Zhang L, Kiick KL, Furst EM. Biomacromolecules 2005;6:1931-1940. [PubMed: 16004430]

(9). Zhang L, Furst EM, Kiick KL. J. Controlled Release 2006;114:130-142.

(10). Cai SS, Liu YC, Shu XZ, Prestwich GD. Biomaterials 2005;26:6054-6067. [PubMed: 15958243]

(11). Pratt AB, Weber FE, Schmoekel HG, Muller R, Hubbell JA. Biotechnol. Bioeng 2004;86:27-36. [PubMed: 15007838]

(12). Tae G, Scatena M, Stayton PS, Hoffman AS. J. Biomater. Sci., Polym. Ed 2006;17:187-197. [PubMed: 16411608] 
(13). Wissink MJB, Beernink R, Pieper JS, Poot AA, Engbers GHM, Beugeling T, van Aken WG, Feijen J. Biomaterials 2001;22:2291-2299. [PubMed: 11456069]

(14). Sakiyama-Elbert SE, Hubbell JA. J. Controlled Release 2000;65:389-402.

(15). Lee KY, Peters MC, Anderson KW, Mooney DJ. Nature 2000;408:998-1000. [PubMed: 11140690]

(16). Zisch AH, Lutolf MP, Ehrbar M, Raeber GP, Rizzi SC, Davies N, Schmokel H, Bezuidenhout D, Djonov V, Zilla P, Hubbell JA. FASEB J 2003;17:2260-2262. [PubMed: 14563693]

(17). Fairbrother WJ, Champe MA, Christinger HW, Keyt BA, Starovasnik MA. Structure 1998;6:637648. [PubMed: 9634701]

(18). Rodriguez JA, Nespereira B, Perez-Ilzarbe M, Eguinoa E, Paramo JA. Cardiovasc. Res 2005;65:665-673. [PubMed: 15664393]

(19). Shen WY, Lai CM, Graham CE, Binz N, Lai YKY, Eade J, Guidolin D, Ribatti D, Dunlop SA, Rakoczy PE. Diabetologia 2006;49:1690-1701. [PubMed: 16752188]

(20). Zhang LL, Hannay JAF, Liu JH, Das P, Zhan MC, Nguyen T, Hicklin DJ, Yu DH, Pollock RE, Lev D. Cancer Res 2006;66:8770-8778. [PubMed: 16951193]

(21). Neufeld G, Cohen T, Gengrinovitch S, Poltorak Z. FASEB J 1999;13:9-22. [PubMed: 9872925]

(22). Arora N, Masood R, Zheng T, Cai J, Smith DL, Gill PS. Cancer Res 1999;59:183-188. [PubMed: 9892205]

(23). Backer MV, Backer JM. Protein Expression Purif 2001;23:1-7.

(24). Backer MV, Backer JM. Bioconjugate Chem 2001;12:1066-1073.

(25). Backer MV, Patel V, Jehning BT, Backer JM. Bioconjugate Chem 2006;17:912-919.

(26). Tirand L, Frochot C, Vanderesse R, Thornas N, Trinquet E, Pinel S, Viriot ML, Guillemin F, BarberiHeyob M. J. Controlled Release 2006;111:153-164. 


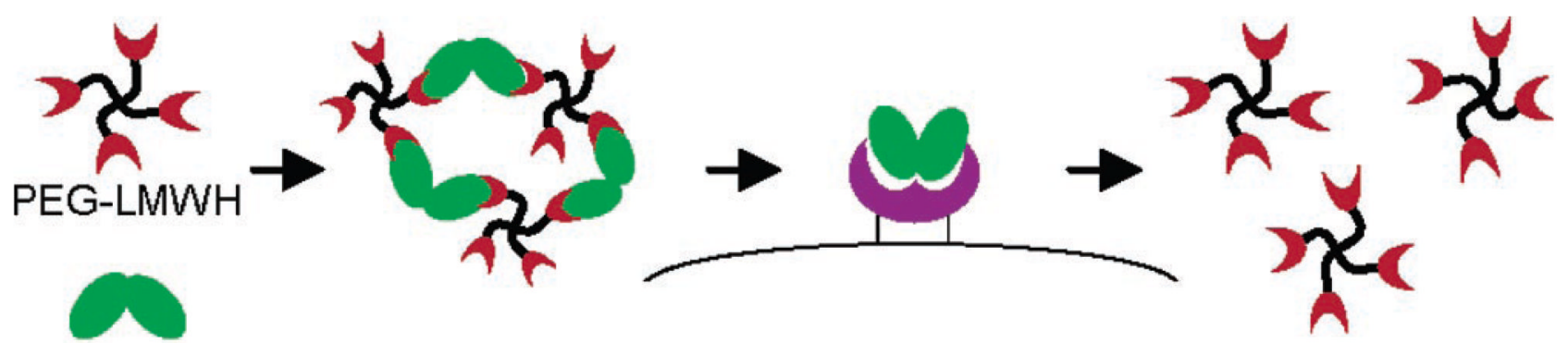

VEGF

Hydrogel erosion

Figure 1.

Schematic of hydrogel formation via the crosslinking of polysaccharide-derivatized star copolymers by dimeric, heparin-binding growth factors, followed by receptor-mediated erosion. 

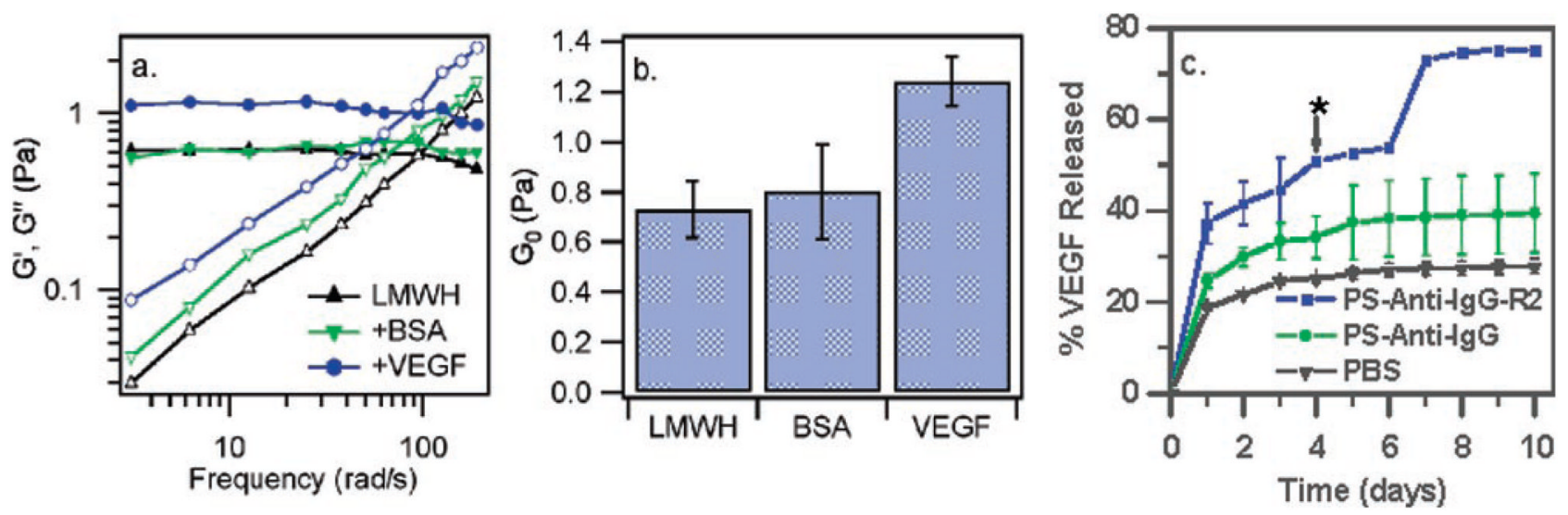

Figure 2.

(a,b) Optical tweezer microrheological characterization of the viscoelastic properties of VEGFcrosslinked hydrogels; (c) release of vascular endothelial growth factor from VEGFcrosslinked hydrogels as a function of time in the absence and presence of the VEGFR-2 receptor. The average of duplicate measurements of separate samples is shown. 

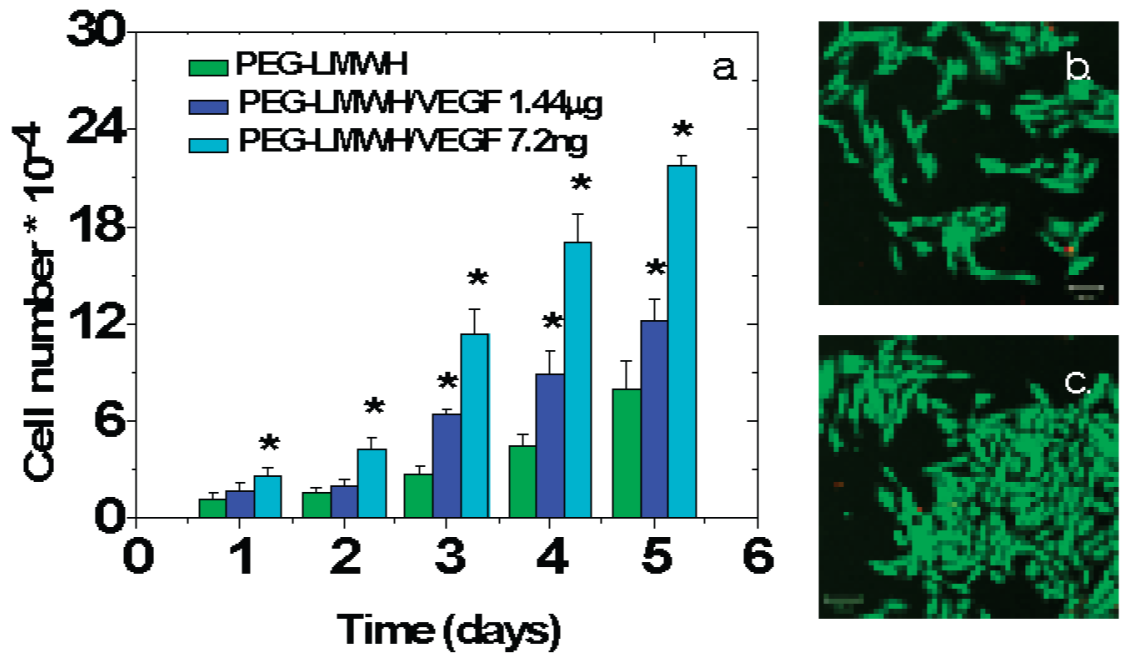

Figure 3.

(a) Proliferation of PAE KDR cells in the presence of PEGLMWH or hydrogels crosslinked with vascular endothelial growth factor; (b) confocal microscopy image of cells, incubated with PEG-LMWH, in a live/dead assay; (c) confocal microscopy image of cells, incubated with PEG-LMWH/VEGF, in a live/dead assay. 